\title{
Dynamic Phenomena Studied with a CCD Detector
}

\author{
C.M. Brizard, B.G. Rodricks and E.E. Alp \\ Advanced Photon Source \\ Argonne National Laboratory \\ 9700 South Cass Avenue \\ Argonne, IL 60439 \\ R. MacHarrie \\ AT\&T Bell Laboratories \\ Murray Hill, NJ
}

August, 1991

$\mathrm{cz}$

*This work supported by the U.S. Department of Energy, BES-Materials Sciences, under contract no. W-31-109-ENG-38

\section{DISCLAIMER}

This report was prepared as an account of work sponsored by an agency of the United States Government. Neither the United States Government nor any agency thereof, nor any of their employees, makes any warranty, express or implied, or assumes any legal liability or responsibility for the accuracy, completeness, or usefulness of any information, apparatus, product, or process disclosed, or represents that its use would not infringe privately owned rights. Reference herein to any specific commercial product, process, or service by trade name, trademark, manufacturer, or otherwise does not necessarily constitute or irmply its endorsement, recommendation, or favoring by the United States Government or any agency thereof. The views and opinions of authors expressed herein do not necessarily state or reflect those of the United States Government or any agency thereof. 


\title{
DYNAMIC PHENOMENA STUDIED WITH A CCD DETECTOR
}

\author{
C. M. Brizard, B. G. Rodricks and E. E. Alp \\ Advanced Photon Source, Argonne National Laboratory \\ Argonne, Il 60439 \\ R. MacHarrie \\ AT\&T Bell Laboratories, Murray Hill, NJ 07974
}

\begin{abstract}
A new programmable charge coupled device (CCD) detector based on the CAMAC (Computer Automated Measurement and Control) modular system and coupled to a MicroVax III computer has been developed for time-resolved synchrotron experiments. The programmability of the electronics allows one to use many kinds of CCD chip. Moreover, different detector modes can be chosen according to the time scale of the experiment. Varlous time-resolved $x$-ray scattering experiments have already been performed at NSLS and CHESS with this imaging system. For example, a real-time study of the early stages of crystallization of the amorphous metallic alloy $\mathrm{Fe}_{80} \mathrm{~B}_{20}$ was carried out at the X6 beamline at NSLS. Here a spin melt ribbon of the amorphous metal was resistively heated in stages to $600^{\circ} \mathrm{C}$ and the crystallization observed on the CCD. The detector angular acceptance of $3^{\circ}$ allowed for the observation of the evolution of the $\alpha-\mathrm{Fe}, \mathrm{Fe}_{3} \mathrm{~B}$ and the $\mathrm{Fe}_{2} \mathrm{~B}$ phases simultaneously on a minute time scale.
\end{abstract}

\section{INTRODUCTION}

Some extremely powerful synchrotron radiation sources, namely, the $6-\mathrm{GeV}$ European Synchrotron Radiation Facilities (ESRF), the 7-GeV Advanced Photon Source (APS), and the 8-GeV Super Positron Ring (SPring-8) are currently under construction. These high brilliance machines coupled with fast position sensitive detectors leads to some exciting time-resolved experiments. $1,2,3,4$

One such exciting field is the in-situ crystallization of amorphous metallic alloys. Metallic glasses, regardless of the way in which they are prepared are not in configurational equilibrium but are relaxing slowly by a homogeneous process towards an "ideal" metastable amorphous state of lower energy. The amorphous state inherently possesses the possibility of transforming into a more stable crystalline state. However, the most promising properties of metallic glasses, e.g., the excellent magnetic behavior or the high hardness and strength combined with ductility and high corrosinr resistance, have been found to deteriorate drastically during crystallization. Understanding the micromechanisms of crystallization to impede or control crystallization is, therefore, a prerequisite for most applications, as the stability against crystallization determines their effective work limits. On the other hand, controlled crystallization of metallic glasses can be used for designing very special partially or fully crystallized microstructures that cannot be obtained from the liquid or crystalline states. In addition to technological interest, crystallization behavior is attracting an increasing scientific interest. 5

As one of the instrumentation projects of the APS, an entirely new CCD-based programmable detector for $x$-ray experiments has $b_{c}$ en developed. The detector with its dedicated CAMAC crate based microprocessor can perform real-time image display and 
manipulation. The microprocessor coupled with the programmability of the arbitrary waveform generators, that are necessary to read out a $C C D$, enables one to use most commercially available $\mathrm{CCD}$ chips as the detector active element. ${ }^{6}$ This detector has the option of being used with direct $\mathrm{x}$-rays or having a phosphor front end coupled to a focussing element.

\section{CCD (CHARGE COUPLED DEVICE) DETECTOR}

The control electronics for the detector is a CAMAC-based system, which is flexible enough to satisfy the readout sequences necessary for most commercially available CCDs. It consists of a CAMAC crate which houses the arbitrary waveform generators, master clock, 12 bit ADC module, $12 \times 1 \mathrm{M}$ memory module, display driver, and LSI-11 dedicated microprocessor. Global control is accomplished by a MicroVax III. Comunication between it and the LSI is through encoded interrupt bit patterns in the form of Look-at-me (LAMs) received by the interrupt register. The LAMs are transmitted through an output register that is accessed by both computers. The main functions of the LSI are:

1) Controlling waveforms sequencing necessary for normal readout, fast clearing, and integration period.

2) Performing displays on a high resolution color monitor, such as full color contour maps, row slice through a particular section of the CCD, data histogramming, etc. All display is carried out through CAMAC with the LSI reading data from the memory module. This feature has the advantage of being an efficient diagnostic tool as the data do not have to be transferred to the MicroVax III.

3) Informing the MicroVax when the LSI's operation is completed so that the MicroVax can decide what function should be done next.

4) Resetting of all modules when necessary.

The heart of the flexibility lies in the interaction between the LSI and the arbitiary waveform generators. Each generator has two 4095 array data banks. The informations written in them correspond to the waveform shape and time required to readout a single row of data from the CCD, to clear or integrate. The data bank does not have to be written completely. These modules are driven by a clock pulse from a master clock generator. The master clock module is programmed to output a burst of square waveforms, whose number corresponds exactly to the number of memory cells written in the waveform generator. During normal readout, a single burst corresponds to tie reading of a single row of data. At the end of each burst, it sends a LAM to the LSI, which decreases a counter ccrresponding to the number of rows in that particular CCD and restarts the burst to read another row. This continues until all the rows are readout, at the end of which, it informs the MicroVax that the CCD data are stored in memory. The MicroVax has the option of reading the data onto the hard disk or requesting the LSI to display it. The LSI is responsible for switching banks to obtain the necessary waveforms that are required during the clear and integration cycles. Another clock module acts as the convert pulse to digitize the data to 12 bits in the ADC module. This module is also triggered by the clock burst from the master clock, and hence, is enabled only during serial readout. Because the LSI controls the transfer, a delay of about $20 \mu \mathrm{s}$ between rows results.

This system, in which the LSI keeps track of the number of rows the CCD possesses and the arbitrary waveform generators have the information required to readout the $C C D$, allows one to program the system for different chips. All outputs from CAMAC go to a connector strip that has a 16-pin cable connected to the CCD vacuum chamber. Depending on the $C C D$ in use, the outputs are connected to the strip such that the 16 pins supply the correct pins on the CCD. 
The software currently supports the following three chips, namely, TI 4849, TC 215 , manufactured by Texas Instruments; and TH 7883, manufactured by ThomsonCSF. The TI 4849 is a $390 \times 584$ pixels device, with each pixel being $22.4-\mu \mathrm{m}^{2}$, the TC 215 is a $1024 \times 1024$ pixel device, with each pixel being $12-\mu \mathrm{m}^{2}$, and the TH 7883 is a $384 \times 576$ pixel device with each pixel $23-\mu \mathrm{m}^{2}$. The chip currently used for this time-resolved $x$-ray experiment was the TI 4849.

The CCD is Peltier-cooled $\left(-40^{\circ} \mathrm{C}\right)$ and placed in a vacuum chamber to prevent condensation on the sensitive face of the CCD chip. The front end of this chamber can be either a quartz window connected to an optical system ${ }^{7}$ or a beryllium window for direct $\mathrm{x}$-ray applications (Fig. 1). For the first case, the $\mathrm{x}$-ray photons are converted into visible light through a phosphor. A variety of phosphor screens have been used: $\mathrm{Gd}_{2} \mathrm{O}_{2} \mathrm{~S}$ : Tb (Trimax 2 - 3M), LaOBr:Tm combined with $\mathrm{Gd}_{2} \mathrm{O}_{2} \mathrm{~S}$ : Tb (Quanta V - Du Pont), and $\mathrm{CaWO}_{4}$ (Hi-Plus - Du Pont). Overall efficiencies of conversion for $\mathrm{x}$-ray energy to light energy within the phosphor are typically 10-20\%. For an $x$-ray energy of $7 \mathrm{KeV}(1.77 \AA)$, a light wavelength of $0.5 \mu \mathrm{m}(2.5 \mathrm{eV})$, and a conversion efficiency of $10 \%, 280$ optical photons are produced for a single $x$-ray photon. Assuming Lambertian emission in the phosphor, the efficiency with which a lens conveys light is approximately: 8

$$
\mathrm{C}=[\mathrm{M} / 2 \mathrm{f}(1+\mathrm{M})]^{2}
$$

where $M$ is the image to object magnification and $f$ is the lens " $f$ " number. This equation indicates that lens coupling is inherently inefficient and rarely exceeds a few percent (Fig. 2). It has been estimated that each $\mathrm{x}$-ray photon gives rise to two optical photons at the CCD with the coupling of the two Nikon lenses $50 \mathrm{~mm} / \mathrm{F} 1.2$ and 200 $\mathrm{mm} / \mathrm{F} 4 .{ }^{9}$ Estimating a quantum efficiency of 0.5 for the $\mathrm{CCD}$ chip at a $0.5 \mu \mathrm{m}$ wavelength, one photoelectron is generated for two visible photons. Thus, one photoelectron is generated per $x$-ray photon striking the phosphor screen.

The efficiency of the TI 4849 has also been determined directly with $x$-rays of 7 $\mathrm{KeV}$ and found to be one photoelectron generated per incident $\mathrm{x}$-ray photon. Direct $\mathrm{x}$ ray imaging is exclusively used for fast time-resolved experiments because of practical details like positioning of the slits and decay time of the phosphor. The previous comparaison shows that even for second or minute experiments, the use of direct $x$-ray imaging is attractive. The same global yield is obtained. For $x$-ray experiments that did not require any magnification or demagnification, the $x$-ray imaging setup has been used whatever the time scale, because of its simplicity.

Three modes used for the detector have been set up. ${ }^{10}$ The first mode consists in the reading of the full CCD frame in, typically, $1 \mathrm{~s}$. For the second mode, a slit, whicis is a few rows wide, is physically put in front of the CCD chip. The exposed lines are shifted down into the serial register. This mode allows us to increase the statisitics without significant increase in data collection time. The time resolution in this case is 20 $\mathrm{ms}$, coming from the data transfer time between the buffer memory and the hard disk. For the third mode, a slit of one row wide is put at the top of the chip. The row exposed is shifted down towards the output register. When the top row arrives in this register, the entire chip is read out in the frame mode. The time resolution is $2 \mu \mathrm{s}$, the limit coming from the high capacitance of the CCD row. 


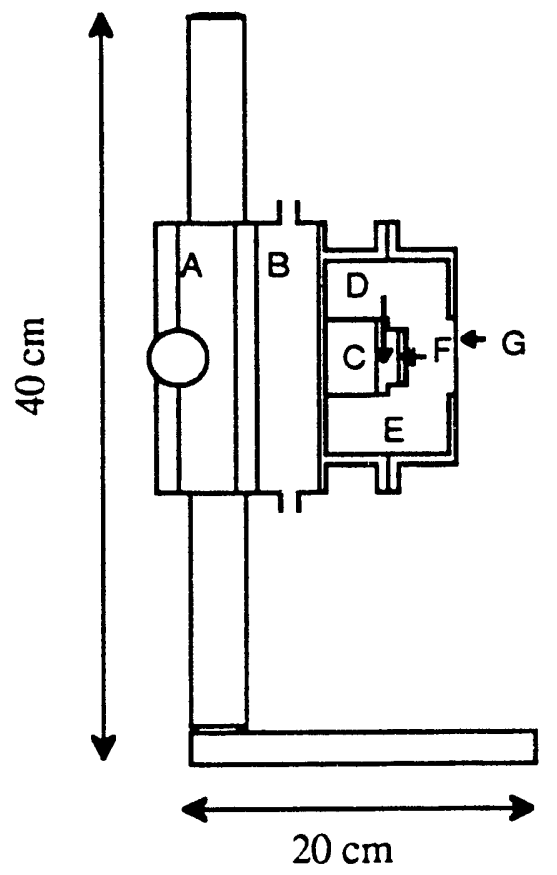

Fig. 1: CCL detector: A) vertical height mounting assembly, B) water-cooled base, C) heat sink, D) Peltier cooler, vacuum chamber, F) $C C D$ chip, G) Beryllium window chamber

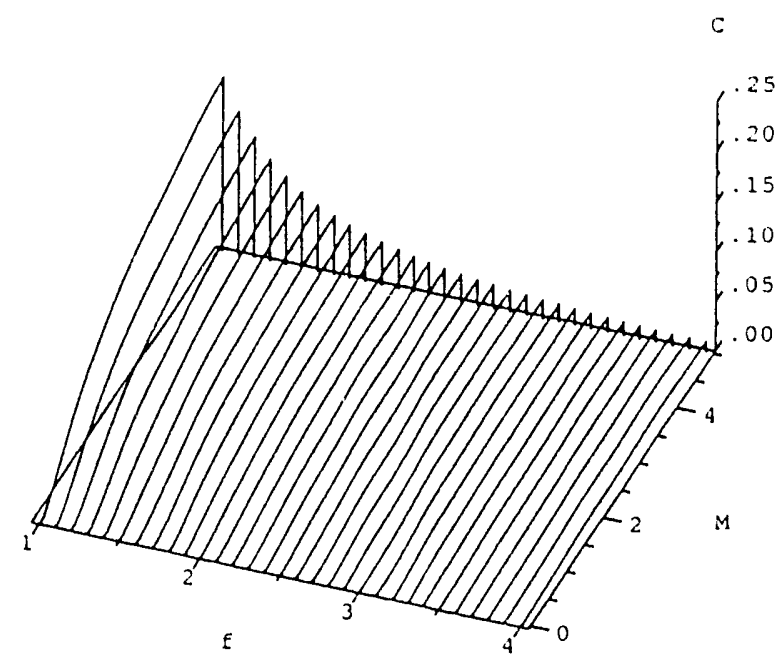

Fig. 2: 3D plot of the efficiency of a lens with a Lambertian emission in the phosphor. The 2 parameters are the " $\mathrm{f}$ " number of the lens and the image to object magnification, $\mathrm{M}$.

\section{CRYSTALLIZATION OF METALLIC GLASSES}

The early stages of crystallization of the compound $\mathrm{Fe}_{80} \mathrm{~B}_{20}$ have been studied for the first time at this time scale (a few minutes) and in this temperature range (from

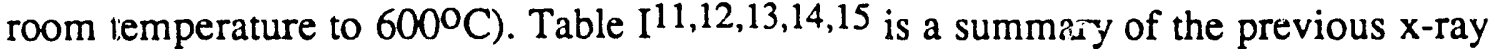
work done on this compound: the time scale is usually in the hour range and/or the temperature range is $600^{\circ} \mathrm{C}-1000^{\circ} \mathrm{C}$.

The beamline used for these experiments has a flat double-crystal Si (220) monochromator that allows one to tune the photon energy. The energy was chosen to be $7 \mathrm{keV}(1.77 \AA)$, which is just below the Fe fluorescence edge. A rocking curve of $\mathrm{Si}$ (100) using the (400) reflection gives an energy spread of $1 \times 10^{-3}$. The flux is $5 \times 10^{9}$ $\mathrm{ph} / \mathrm{s} / \mathrm{mm}^{2}$ for an electron beam intensity of $200 \mathrm{~mA}$.

The in-situ crystallization was performed in the vertical geometry, and the detector was mounted on the 2-theta arm of the diffractometer. The diffraction patterns of a polycrystalline sample are cones of semi-apex angle $2 \theta .{ }^{16}$ The main $\alpha-F e$ reflection is located at a $2 \theta$ angle of $51.83^{\circ}$. At the location of the CCD chip $(17 \mathrm{~cm}$ from the sample), the diffracted pattern corresponds to a large circle of radius $216 \mathrm{~mm}$. The 13 $\mathrm{mm}$ long chip intercepts $0.06 \mathrm{rad}\left(3.5^{\circ}\right)$. The maximum distance between the intercepted arc and its chord is $60 \mu \mathrm{m}$ on the CCD chip plane ( 3 pixels). This distance is much smaller than the intrinsic variation of the peak position, typically 20 pixels 
(corresponding to $2.6 \times 10^{-3} \mathrm{rad}$ ), due to inhomogeneities (crystallites size). So, the diffracted peaks can be assumed to be parallel to the columns of the CCD chip. Hence, the rows can be summed in order to improve the statistics (Fig. 3). If the phenomenum to be studied is faster than a few seconds, the rows would be summed in the serial register of the chip itself. On the other hand, if the time constant of the phenomenum is larger than a few seconds, frames would be recorded, typically every few seconds, and rows can be added later by the software. As the kinetics of the crystallization of Fe $80 B_{20}$ are quite slow, the second method was used.

Table I: X-ray diffraction for crystallization studies of Fe80B20 amorphous alloys.

Reference Heat treatment

[11]

$$
\begin{aligned}
& T=780^{\circ} \mathrm{C}, \Delta t=1 \mathrm{~s}-8 \mathrm{~h} \\
& \mathrm{~T}=300^{\circ} \mathrm{C}-900^{\circ} \mathrm{C}, \Delta \mathrm{T} / \Delta \mathrm{t}=100^{\circ} \mathrm{C} / \mathrm{h}, \Delta \mathrm{t}=1 \mathrm{~h} . \\
& \mathrm{T}=400^{\circ} \mathrm{C}-1000^{\circ} \mathrm{C}, \Delta \mathrm{T} / \Delta \mathrm{t}=15^{\circ} \mathrm{C} / \mathrm{h} \\
& \mathrm{T}=300^{\circ} \mathrm{C}-900^{\circ} \mathrm{C}, \Delta \mathrm{t}=1 \mathrm{~h}-2 \mathrm{~h} \\
& T=300^{\circ} \mathrm{C}-600^{\circ} \mathrm{C}, \Delta \mathrm{t}=1 \mathrm{~h}
\end{aligned}
$$

$\mathrm{T}$ is the temperature range at which data were recorded. $\Delta \mathrm{T} / \Delta \mathrm{t}$ was the heating rate. $\Delta \mathrm{t}$ is the period during which a sample was heated at a constant temperature.

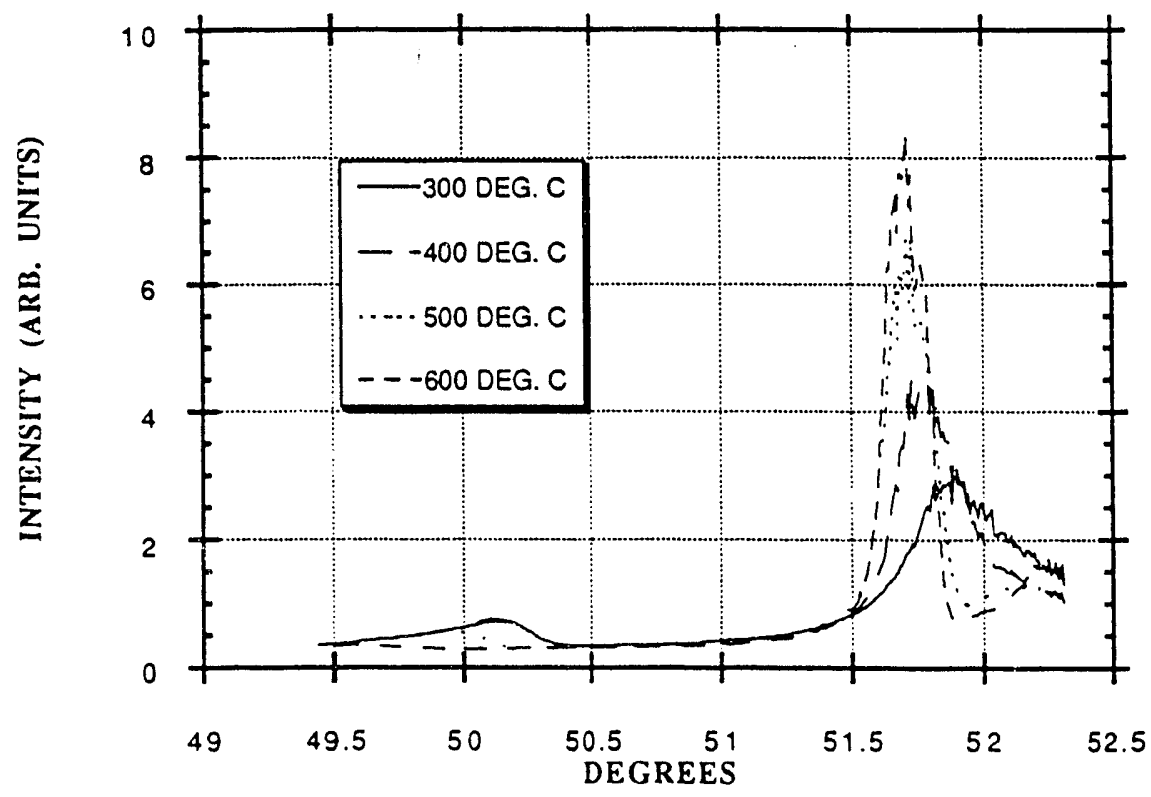

Fig. 3: CCD row sums of the diffracted peaks of Fe80B20. 
The Fe80B20 ribbons are resistively heated ( $\mathrm{I} \approx \mathrm{a}$ few Amps, $\mathrm{V} \approx \mathrm{a}$ few Volts) in a small vacuum chamber in order to prevent the oxidation of this Fe compound. Isothermal x-ray diffraction spectra are recorded at temperatures from $300^{\circ} \mathrm{C}$ to $600^{\circ} \mathrm{C}$. The field of view of the CCD chip allows one to record simultaneously several diffracted peaks. The $\mathrm{Fe}_{3} \mathrm{~B}$ (321), $\alpha$-Fe (110), and $\mathrm{Fe}_{2} \mathrm{~B}$ (211) peaks are observed respectively at $2 \theta=50.20^{\circ}, 51.83^{\circ}$, and $52.21^{\circ}$. The fastest crystallization is detected in $11 \mathrm{~min}$ as the sample is heated progressively from room temperature to $380^{\circ} \mathrm{C}$. This is the first time that the $\mathrm{Fe} 80 \mathrm{~B} 20$ crystallization is detected at such an early stage at low temperature.

A summary of the results ${ }^{17}$ (Fig. 4) includes: 1) the eutectic crystallization of $\mathrm{Fe}_{3} \mathrm{~B}$ and $\alpha-\mathrm{Fe}$ appears approximately at $300^{\circ} \mathrm{C}$. 2) the metastable $\mathrm{Fe} 3 \mathrm{~B}$ phase disappears around $500^{\circ} \mathrm{C}$ and, simultaneously, the primitive tetragonal $\mathrm{Fe}_{2} \mathrm{~B}$ (211) peak appears. 3) The average grain size of the crystallites increases from $200 \AA$ $\left(300^{\circ} \mathrm{C}\right)$ to $1000 \AA\left(600^{\circ} \mathrm{C}\right)$. 4) The main peak shift has been related to an intrinsic physical behavior related to the increase of the d-spacing. (Note that the position of the small peak [Fe3B] does not change at all; the displacement of the main peak doesn't come from a displacement of the sample. Moreover, the thermal dilatation contribution represents only $10 \%$ of this shift.) The d-spacing variation comes from the existence of a supersaturated solution of $\alpha-\mathrm{Fe}(\mathrm{B})$. This behavior has already been found in some Fe-B systems. ${ }^{11}$ It is emphasized that this finding of the existence of a single phase of $\alpha-\mathrm{Fe}(\mathrm{B})$ just after the crystallization is important, because no report on this point has been found in the literature for $\mathrm{Fe} 8 \mathrm{~B}^{\mathrm{B}} 20$. The $\mathrm{B}$ migratic 1 out of the $\alpha$-Fe matrix takes time following the crystallization and phase separation process. With the CCD camera, we are able to observe, for the first time, $\alpha$-Fe supersaturated with $B$. This observation is not possible with traditional techniques like Mössbauer spectroscopy, which takes a few days, or even with interrupted quench techniques coupled to x-ray diffraction.

\section{CONCLUSION}

A new programmable CCD detector has been developed for time-resolved synchrotron experiments. The versatility of this CAMAC-based system allows one to use many different kinds of commercially available CCD chips. This device can monitor rapid thermal annealings, strain relaxations, crystallization kinetics,etc., by recordins, $\mathrm{X}$-ray movies on a time scale from minutes to 2 microseconds. The innovative technique used for the experiments decribed here opens new exciting fields to study transient behaviors in matter as they occur.

The fastest time-resolved $x$-ray experiments will be those using the pulsed nature of the synchrotron beam. At $\mathrm{CHESS}$, for example, the single bunch frequency is 2.56 $\mu \mathrm{s}$, the $\mathrm{x}$-ray burst duration is $160 \mathrm{ps}$ (FWHM), and a typical number of monochromatic $x$-ray photons per burst is $5 \times 10^{4}$. With a synchronization between the $x$-ray bunch arrival and the CCD detector, the time resolution of the detector $(2 \mu \mathrm{s})$ would allow one to record successive bunch profiles of the synchrotron radiation beam. Also, time-resolved experiments for high flux setups could be made at this speed. For "photon-hungry" experiments, various stroboscopy experiments could be carried out with the three different CCD detector modes. The success of such an experiment relies on the synchronization between the coming x-ray bunch, the probe, and the read-out of 
the CCD chip according to the mode used. The photons are accumulated on the same $C C D$ area at different stroboscopic times until a good statistics has been reached. This CCD area, which can be a frame, a few rows, or one row according to the mode used, is transferred. The delay time between the $x$-ray bunch arrival and the probe can be increased and another recording can be made. The resolution of this system is as high as a few nanoseconds, the time interval between the different delay times.
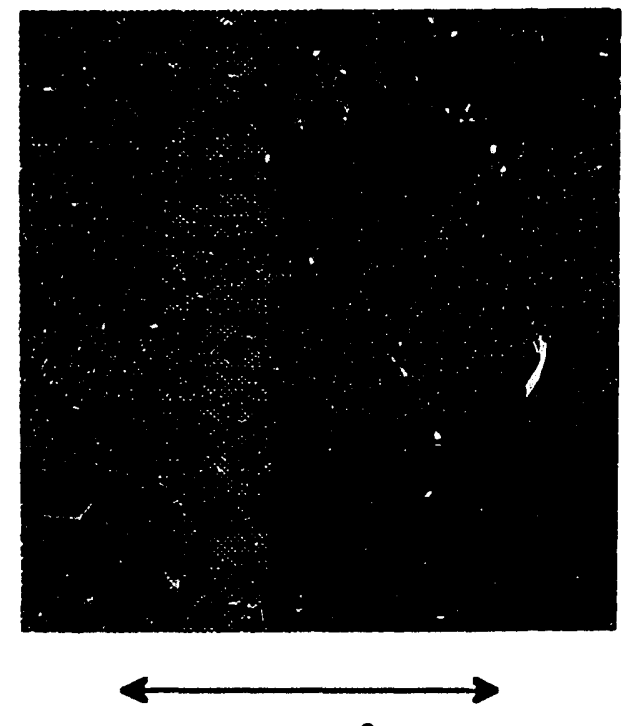

$1.4^{\circ}$

(4a)

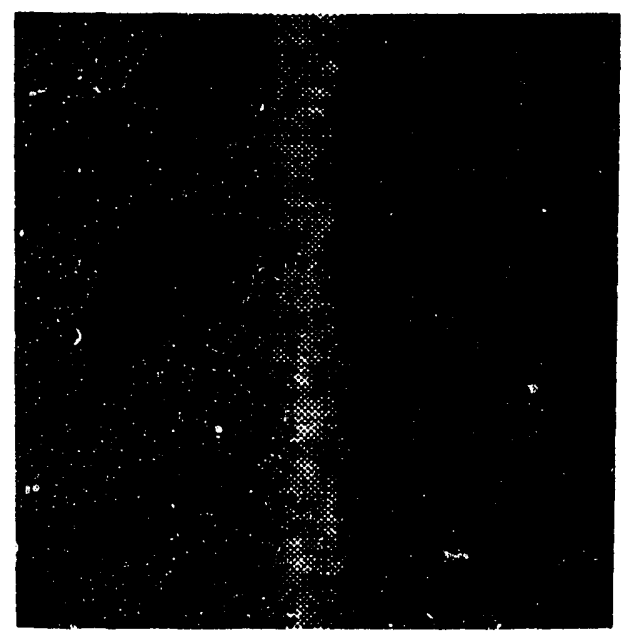

(4c)

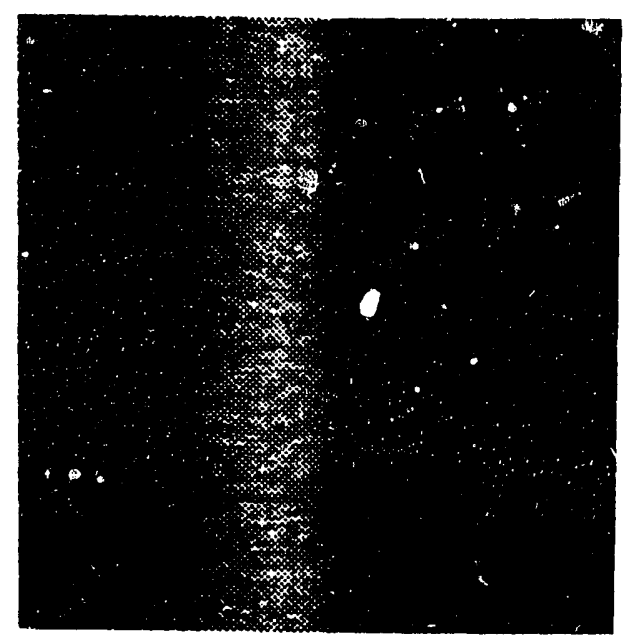

(4b)

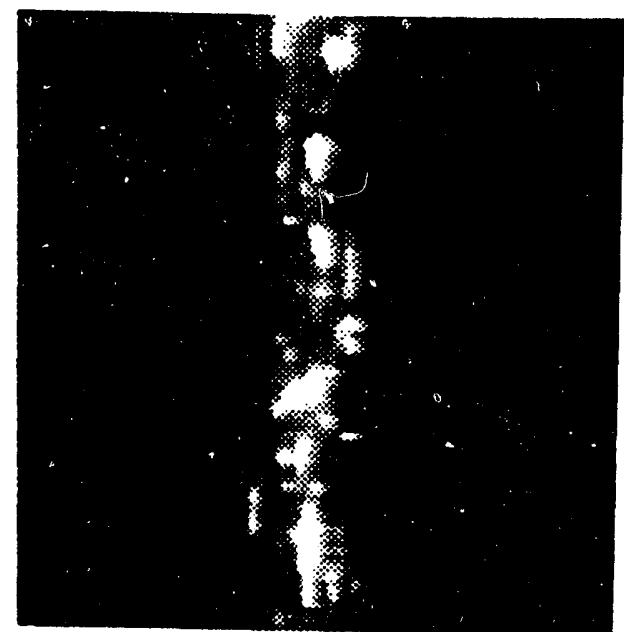

(4d)

Fig. 4: Full $\mathrm{x}$-ray diffraction pictures obtained with the $\mathrm{CCD}$ detector at different temperatures: $300^{\circ} \mathrm{C}(4 \mathrm{a}), 400^{\circ} \mathrm{C}(4 \mathrm{~b}), 500^{\circ} \mathrm{C}(4 \mathrm{c}), 600^{\circ} \mathrm{C}(4 \mathrm{~d})$. The peaks become more intense and sharper as the temperature increases. At $600^{\circ} \mathrm{C}$, very intense spots reveal the presence of large crystallite sizes. 


\section{ACKNOWLEDGEMENTS}

The authors wish to thank Gopal Shenoy for his great support and Dennis Mills for representing us at the "Synchrotron Radiation and Dynamic Phenomena" Conference in Grenoble; Joe Arko and Ron Hopf deserve thanks for their invaluable help assisting us. It is a pleasure to thank Pedro Montano and Marc Engbretson for the use of X6B at NSLS. Roy Clarke and Walter Lowe are also thanked for their helpful discussions. This work is supported by U.S. Dept. of Energy, BES-Materials Science, under grant contract \#W-31-109-ENG-38.

\section{REFERENCES}

1. D.M. Mills, "Time-Resolved Studies" in Handbook on Synchrotron Radiation, Vol.3, ed. D. Moncton and G. Brown (1991).

2. R. Clarke, W. Passos, W. Lowe, B. Rodricks, and C. Brizard, "Real-Time Xray Studies of Strain Kinetics in In $_{\mathrm{X}} \mathrm{Ga}_{1-\mathrm{x}}$ As Quantum Well Structures," Physical Review Letters, 66, N.3, (1991)

3. R. Clarke, W. Dos Passos, W. Lowe, B. Rodricks, and C. Brizard, "Real Time $\mathrm{X}$-Ray Studies of Interface Kinetics in Epitaxial Strained Layers," MRS Spring Meeting, Anaheim (1991).

4. W. Lowe, R.A. MacHarrie, R. Clarke, W. Dos Passos, C. Brizard, and B. Rodricks, "Real-Time X-Ray Diffraction Observation of a Pin-Slip Mechanism in $\mathrm{Ge}_{\mathrm{X}} \mathrm{Si}$ 1-x $_{\mathrm{x}}$ Strained Layers," submitted to Physical Review Letters.

5. ¿ Koster and U. Herold, Glassy Metals I, Ed. H.J. Guntherodt and H. Beck, (Springer-Verlag, 1981) p.225.

6. B. Rodricks and C. Brizard, "A Programmable Imaging System for Synchrotron Studies," accepted for publication to Nucl. Instr. and Meth.

7. C. Brizard and B. Rodricks, "Programmable CCD Imaging System," submitted to Optical Engineering.

8. S.M. Gruner, Rev. Sci. Instrum. $\underline{60}$ (7) 1545 (1989).

9. B. Rodricks, R. Clarke, R. Smither, and A. Fontaine, Rev. Sci. Instrum. $\underline{60}$ (8) 2586 (1989).

10. C. Brizard and B. Rodricks, "Programmable CCD Imaging System For Synchrotron Radiation Studies," to be published in Rev. Sci. Inistrum.

11. O.T. Inal, L. Keller, F.G. Yost, J. Mater. Sci. 15, 1947-1961 (1980).

12. M. Takahashi, M. Koshimura, and T. Abuzuka, Jpn. J. Appl. Phys. 20, 1821$1832(1981)$.

13. Y. Khan, and M. Sostarich, Z. Metallkde. 72, 256 (1981). 
14 J.A. Cusido, A. Isalgue, and J. Tejada, Phys. Stat. Sol. (a) 87, 169 (1985).

15. P. Tlomak, S.J. Pierz, L.J. Paulson, and W.E. Brower, Jr. Mater. Sc. and Engineer. 27, 369-372 (1988).

16. L.H. Schwartz, J.B. Cohen, Diffraction from Materials, (second edition, MRE).

17. C. Brizard, B.Rodricks, E. Alp, and R. MacHarrie, "In situ X-ray Studies of the early stages of Fe80B20 crystallization," submitted to Journal of Materials Science. 

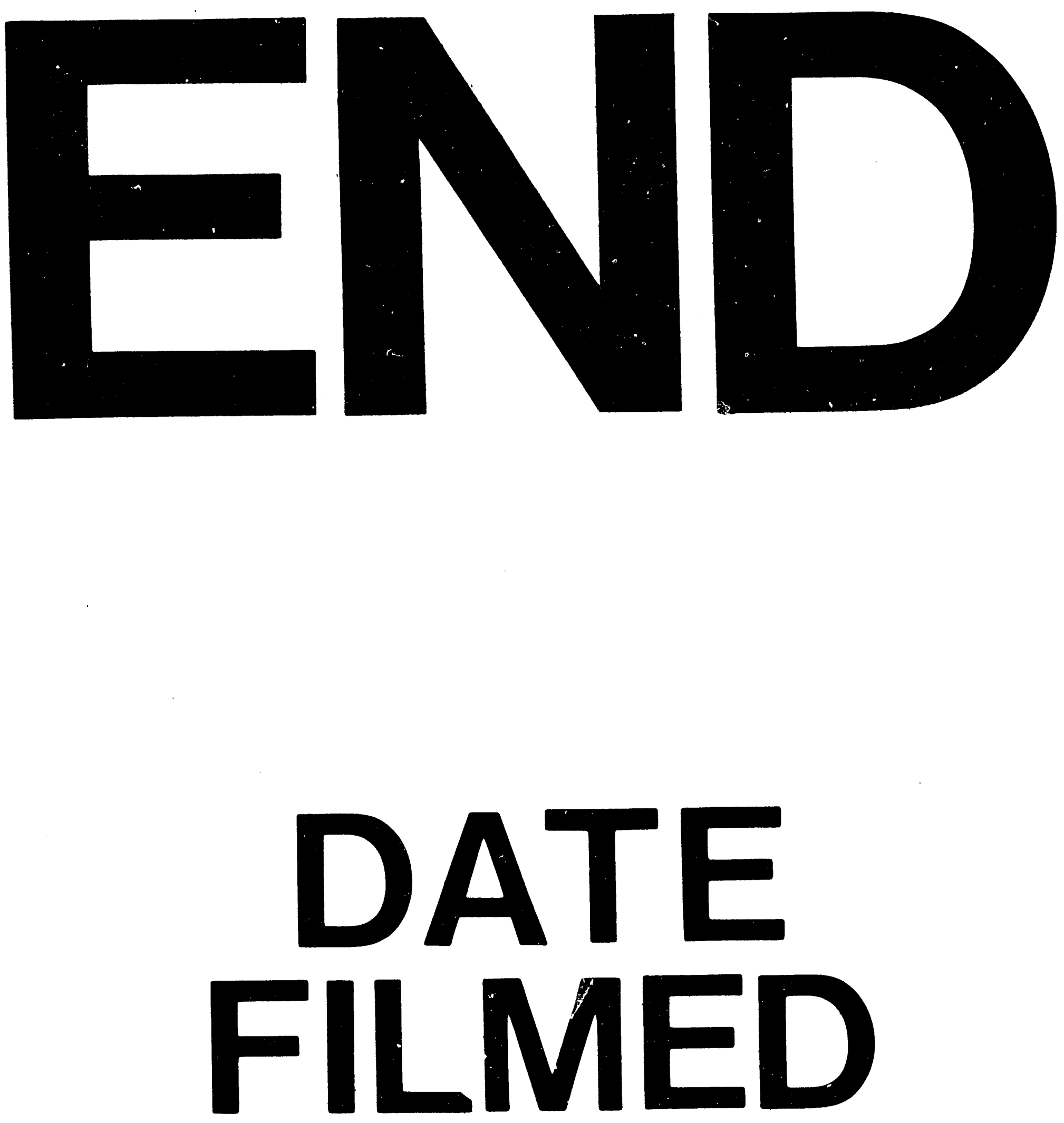

1

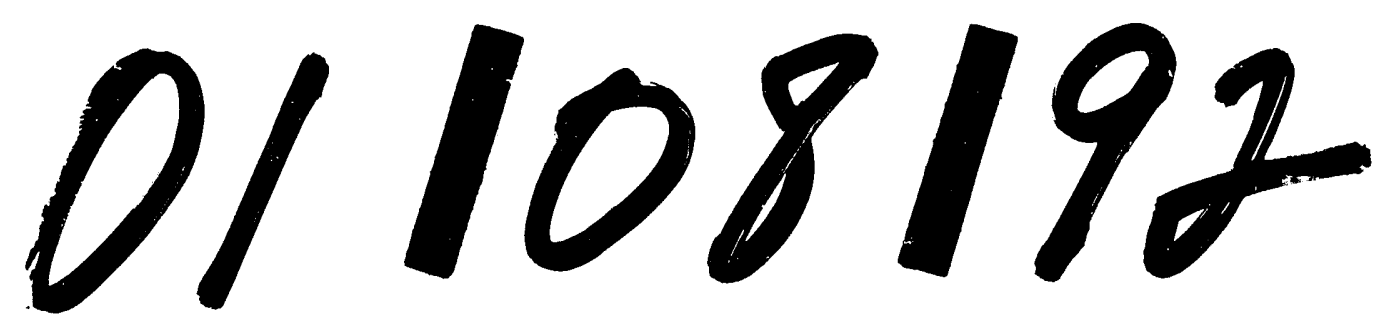


